\title{
EFFECT OF ULTRASONICATION DISPERSION TECHNIQUE ON SINTERING PROPERTIES OF CNT REINFORCED Al-Zn-Mg-Cu POWDER
}

\begin{abstract}
CNT has been researched significantly due to its properties especially mechanical and conductivity properties. Due to strong affinity between particles, dispersion has been remained a problem for its applications. Ultrasonication technique was used to disperse CNT on aluminum powder. Ultrasonication has successfully dispersed CNT on aluminum powder in ethanol. Low energy ball milling for $1 \mathrm{~h}$ under argon gas with 5:1 ball to powder ratio was used to optimize dispersion of CNT on aluminum. CNT concentration in this research is ranged from 0.1 up to $3 \mathrm{wt} \%$. Premix Al-5.5Zn-2.5Mg-0.5Cu powder was used as matrix for this research. Sintering at $580^{\circ} \mathrm{C}$ for $1 \mathrm{~h}$ under argon gas was carried to produce high density materials. Pores are still remained on material and it is possibility that pores were caused by agglomeration of CNT. Dispersion high content of CNT is still remained obstacle on this research. Aluminum carbide, $\mathrm{Al}_{4} \mathrm{C}_{3}$ is recognized as a 'bridge between aluminum and $\mathrm{CNT}$ for stress transfer was investigated in this research. Raman Spectroscopy, XRD and SEM-EDS were carried out to characterize materials.
\end{abstract}

Keywords: Powder Metallurgy, Nanocomposites, Sintering, Aluminum Alloys

\section{Introduction}

Aluminum-CNT composite has been researched with several researchers because of high mechanical properties of CNT. High energy ball milling is commonly used to produce Aluminum-CNT composite with providing good dispersion and mechanical properties. Interface between Aluminum and CNT has been improved by this method. High energy ball milling which includes continuously fracturing and cold welding, it may damage CNT structure and reduce its optimal properties. Impurities may also come from ball mill due to impact of high energy. Iron as impurity to the powder was found as result from continuous contact between Aluminum powder and balls [1-2].

Ultrasonication technique to disperse CNT was used by S. Simoes et al. CNT was well dispersed by this technique. But interface between Aluminum and CNT from this technique was not as strong compared to high energy ball milling as it shows by their mechanical properties behavior [3-4]. Formation of aluminum carbide, $\mathrm{Al}_{4} \mathrm{C}_{3}$ seems to be important factor to have better interface and mechanical properties. Aluminum carbide is able to transfer stress from matrix into reinforcement particle which leads to higher mechanical properties. Formation of aluminum carbide mainly depends on temperature process. On some cases, aluminum carbide was found after high energy ball milling [1-3].
Alumix 431D has shown high sinterability and mechanical properties by reaching sintering density for over than $97 \%$ relative. Alumix 431D is premix powder with aluminum as base powder with additional $\mathrm{Zn}, \mathrm{Mg}$ and $\mathrm{Cu}$. This powder has similarity of chemical composition with AA7075. This powder is also heat treatable, increasing on mechanical properties was shown after T6 heat treatment. Intermetallic phases which responsible for mechanical properties of this powder are $\mathrm{MgZn}_{2}$ and $\mathrm{Al}-$ $\mathrm{CuMg}$ [5-6]. The purpose of this research to investigate effect of ultrasonication dispersion methods of CNT to Alumix 431D.

\section{Experimental method}

Premix Al-5.5Zn-2.5Mg-0.5Cu powder was used as matrix in this research. This powder was named ALUMIX431D and produced by Ecka Granules, Germany. Multi walled CNT was used as reinforcement particles and produced by Sigma Aldrich. This MW CNT has diameter of 5.5nm and length of 6-9 nm. Ultrasonication was done with using Ultrasonication equipment with 0.5 wave length for 30 min under ethanol for $100 \mathrm{ml}$. After ultrasonication, to maximize dispersion of MW CNT on aluminum powder, milling was done with $10 \mathrm{~mm}$ hardened steel ball with 5:1 ball to powder ratio under argon gas and $300 \mathrm{rpm}$ for $1 \mathrm{~h}$.

\footnotetext{
* NETME CENTER, INSTITUTE OF MATERIALS SCIENCE AND ENGINEERING, BRNO UNIVERSITY OF TECHNOLOGY, TECHNICKA 2896/2, BRNO, 61669, CZECH REPUBLIC ** RESEARCH GROUP OF NANOMATERIALS AND COMPOSITE, INSTITUTE OF CHEMICAL TECHNOLOGIES AND ANALYTICS, VIENNA UNIVERSITY OF TECHNOLOGY, GATREIDEMARK, 9/164, A 1060, VIENNA, AUSTRIA

*** MATERIALS RESEARCH CENTER, FACULTY OF CHEMISTRY, BRNO UNIVERSITY OF TECHNOLOGY, PURKYNOVA 118, 61200, BRNO, CZECH REPUBLIC

\# Corresponding Author: harisrudianto@gmail.com
} 
To produce high density materials, compaction followed by sintering under argon gas were carried out. Compaction was done at $700 \mathrm{MPa}$ to produce green body materials with $20 \mathrm{~mm}$ diameter. Vickers hardness was used to measure mechanical properties of sintered materials with $5 \mathrm{lb}$ load and 10 second holding time. SEM-EDS and X-ray Diffraction analysis were used to characterize the structural analysis of the samples. The diffraction patterns of samples were achieved by X-ray diffraction analysis. XRD patterns were obtained using Rigaku Diffractometer with $\mathrm{Cu} \mathrm{K} \alpha$ radiation $(\lambda=0.154 \mathrm{~nm})$ in the range of $2 \theta$ from $20-80^{\circ}$ by the step and scanning speed for $0.02^{\circ}$ and $5^{\circ} \mathrm{C} / \mathrm{min}$. To characterize thermal properties, differential scanning calorimetriy (DSC) was carried out. DSC was measured uing SDT-Q600 DSC manufactured by TA instruments. Powder was heated at a rate of $10^{\circ} \mathrm{C} / \mathrm{min}$ under flowing nitrogen $(100 \mathrm{ml} / \mathrm{min})$.

\section{Results and Discussions}

Morphology of MWCNT powder is shown by Fig. 1. Needle-like morphology is expected for CNT powder. Raman spectroscopy of CNT before and after ultrasonication and low energy ball milling are shown on Fig. 2. There is no big difference on raman shifts on both cases, this indicates that ultrasonication and low energy ball milling did not damage much on carbon structures on MW CNT. Ratio of $\mathrm{I}_{\mathrm{D}}$ and $\mathrm{I}_{\mathrm{G}}$ of non-damaged AlCNT composite will be approximately less than 1 [4]. In case of high energy ball milling which is common method to disperse CNT on aluminum powder will give different on raman shift, because high energy ball milling for long time is able to damage
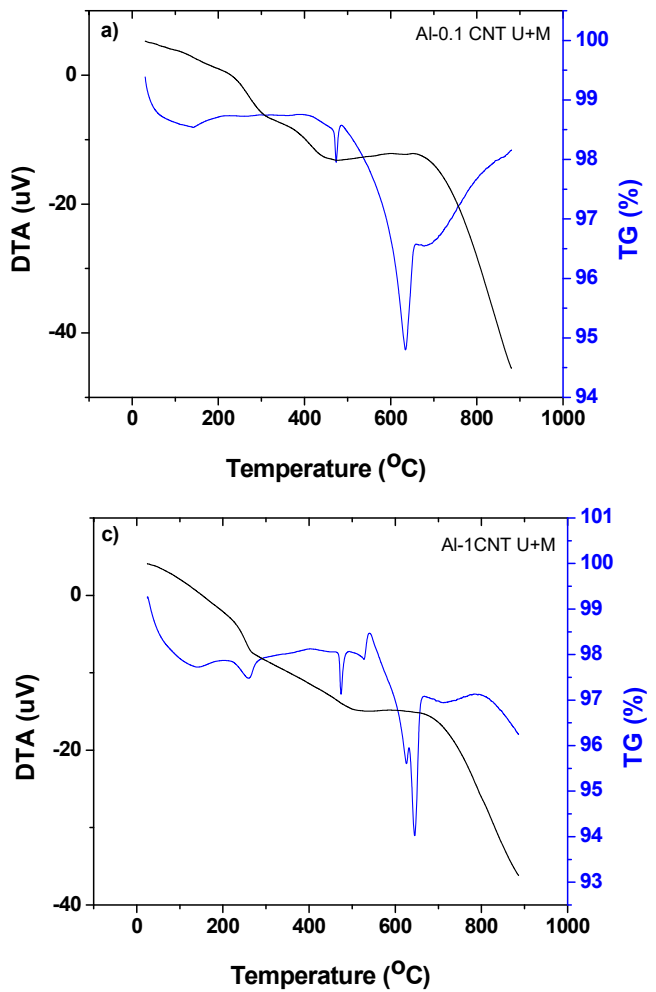
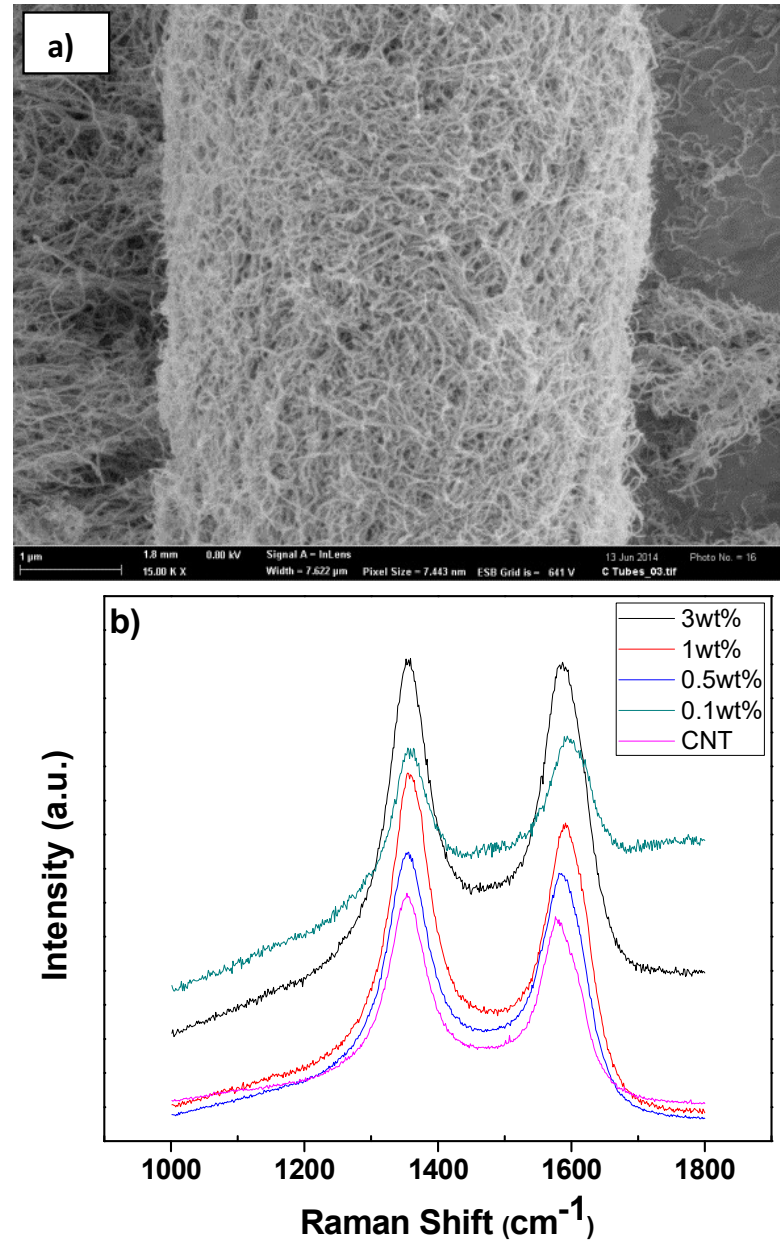

Fig. 1. a) SEM figure of MWCNT powder and b) Raman spectroscopy of as received CNT and after ultrasonication
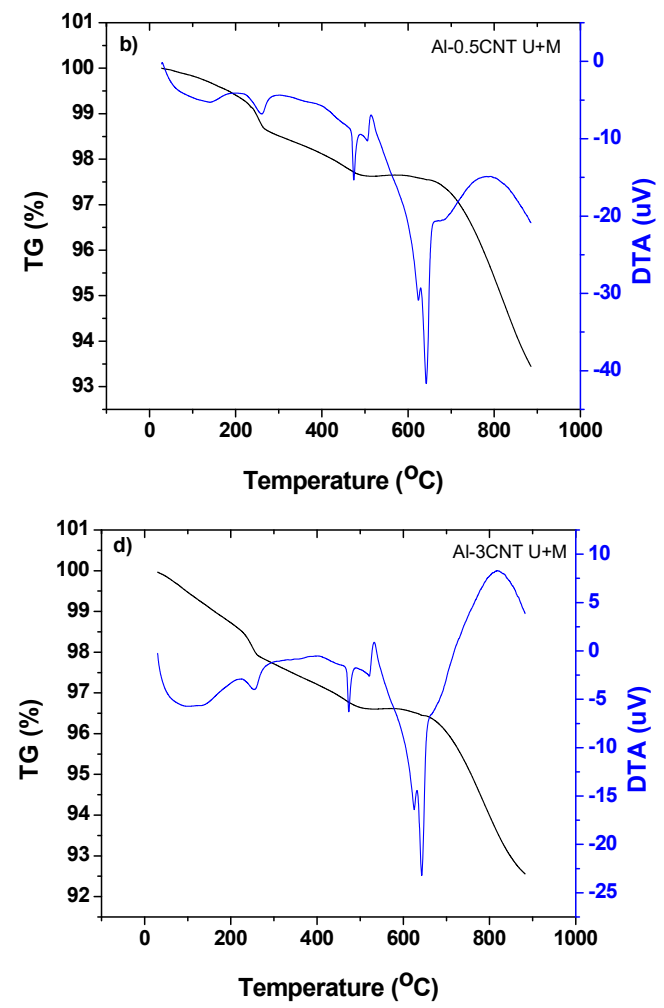

Fig. 2. DSC-TGA of Alumix 431D with a) $0.1 w t . \%$, b) $0.5 \mathrm{wt} . \%$, c) $1 \mathrm{wt} . \%$ and d) $3 \mathrm{wt} . \%$ CNT after ultrasonication 
carbon structure on CNT. But ultrasonication technique is also able to damage CNT structure if done for longer time with high frequency which leads to shortened CNT. After ultrasonication, CNT is able to deagglomerate if the processing time is not sufficient. At least 15 mins ultrasonication for CNT dispersion is required according to Simoes et al results [3].

To estimate sintering temperature, DSC-TGA was carried out as shown at Fig. 2. DSC line for all powders show similar trend with having 2 endothermic peaks. These peaks represent eutectic point for certain materials. First endothermic peak at $450^{\circ} \mathrm{C}$ indicates eutectic point of $\mathrm{Al}-\mathrm{Mg}$ followed by peak at $630^{\circ} \mathrm{C}$ which is eutectic point of Al-Zn. Due to small amount of $\mathrm{Cu}$ content, it is supposed to have eutectic point at $520^{\circ} \mathrm{C}$. From this data of view, sintering temperature is able to estimate. To be able to have liquid phase, sintering temperature must be higher than certain eutectic point. And according to thermogravimetric line (black line), all composites have gone through mass reduction with increasing temperature. The first thermogravimetric line is around $450^{\circ} \mathrm{C}$, it is supposed to be lubricant removal. Lubricant is supposed to be removed before reaching sintering temperature otherwise, it can hinder diffusion process between elements during sintering. $580^{\circ} \mathrm{C}$ sintering temperature was chosen because at that temperature, this alloy powder is able to form optimum liquid phase to be able to achieve optimum sintering density without formation of particle coarsening as shown by previous results [7].
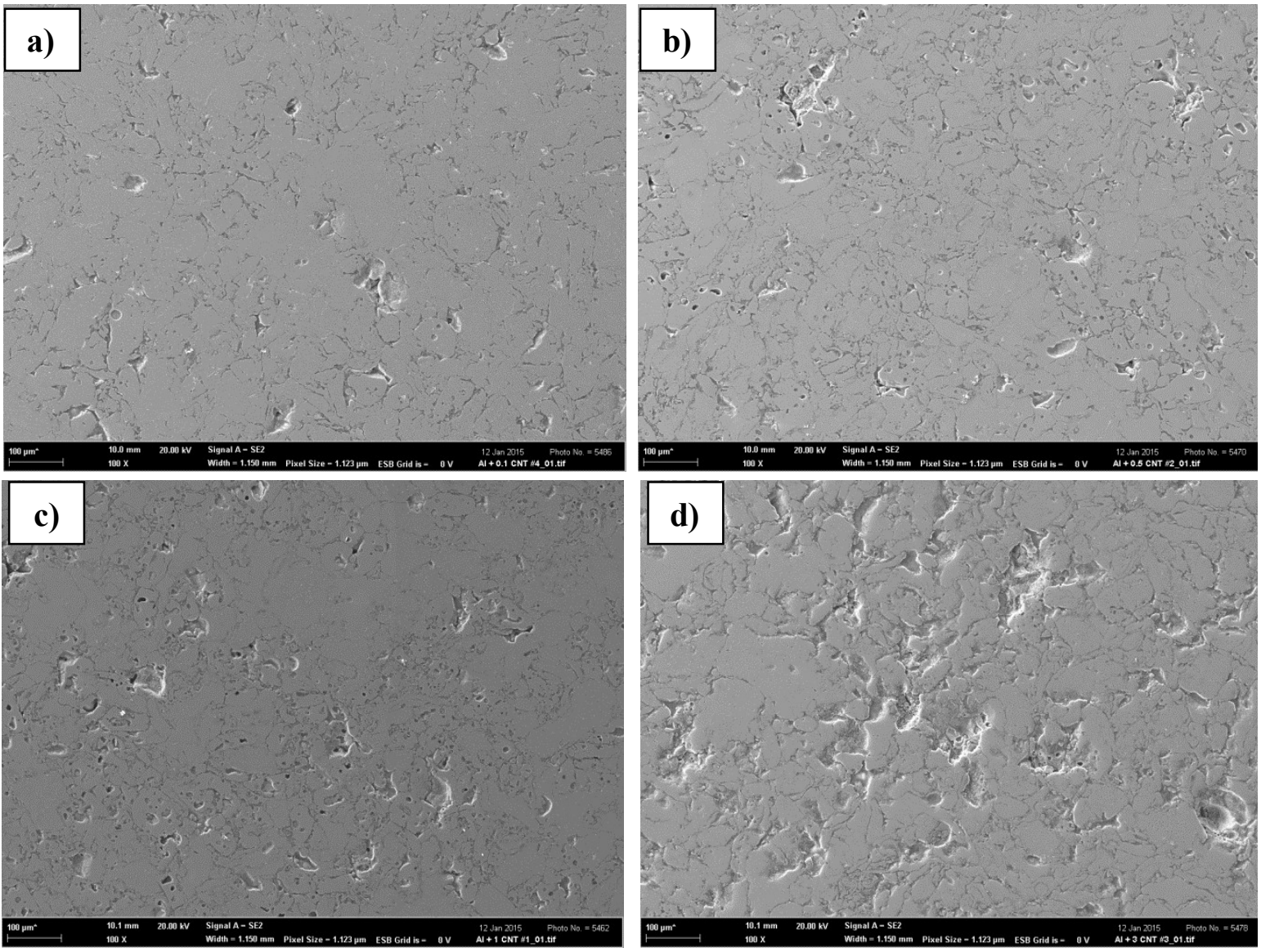

Fig. 3. Mictrostructures after Sintering a) $0.1 \mathrm{wt} . \%$ CNT b) $0.5 \mathrm{wt} . \%$ CNT c) $1 \mathrm{wt} . \%$ CNT d) $3 w t . \%$ CNT 


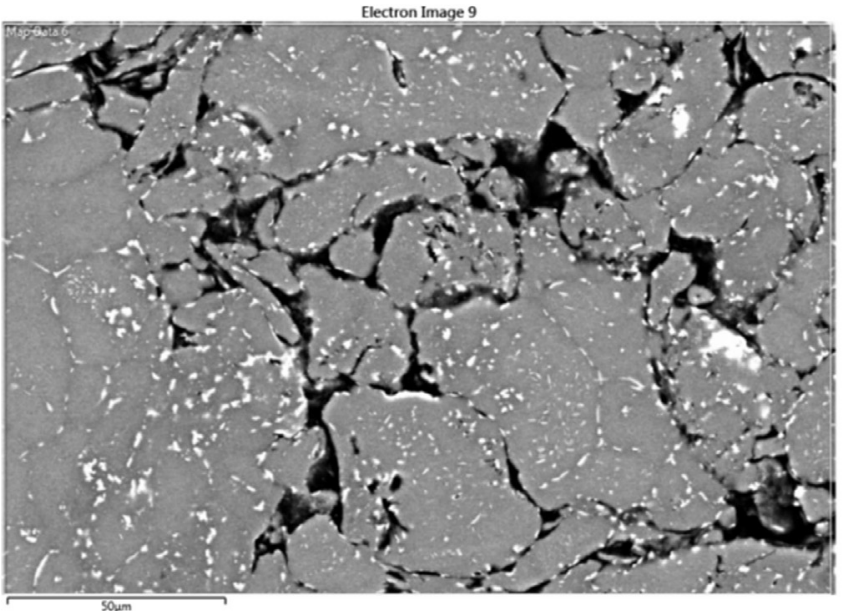

Al K series
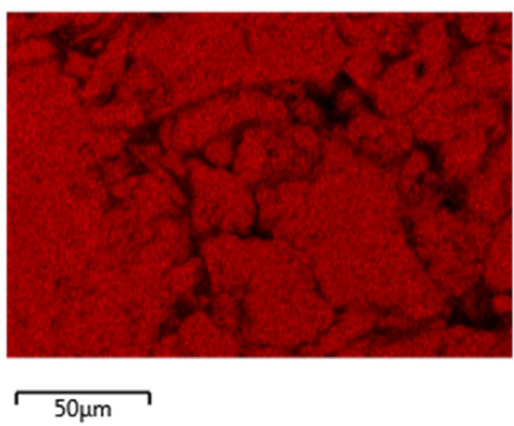

O K series

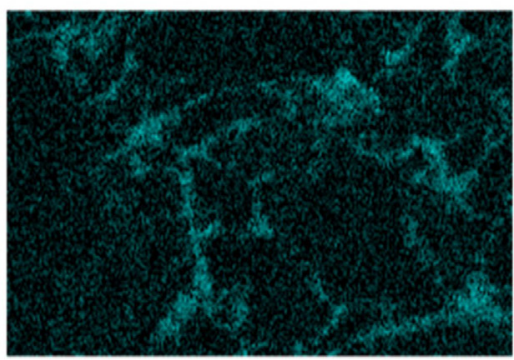

$50 \mu \mathrm{m}$

$50 \mu \mathrm{m}$

$50 \mu \mathrm{m}$
Sn L series

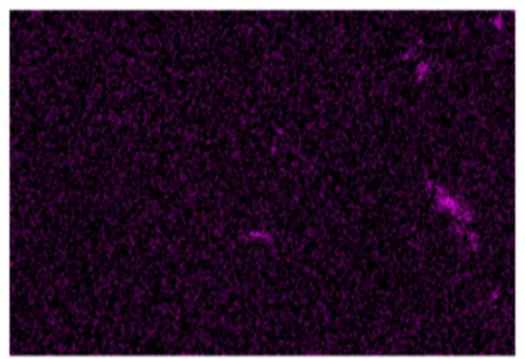

Mg K series

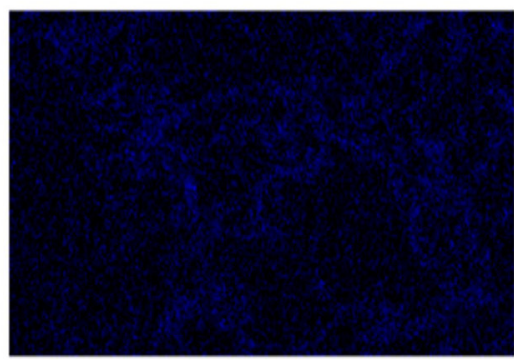

Cu K series

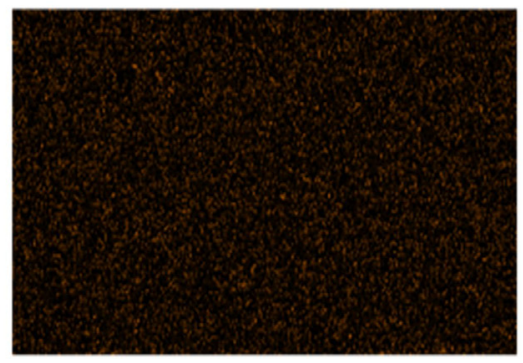

$50 \mu \mathrm{m}$

Fig. 4. EDS analysis of sintered Alumix 431D with 0.1 wt.\% CNT

Aluminum matrix with CNT to be able to transfer the load from matrix to obtain higher mechanical properties. Microstructures also represent mechanical properties of this material as shown by Fig. 5b. Higher content of agglomeration of MWCNT reduced hardness after sintering. And it seems that difficulty may arise

$50 \mu \mathrm{m}$ MWCNT.

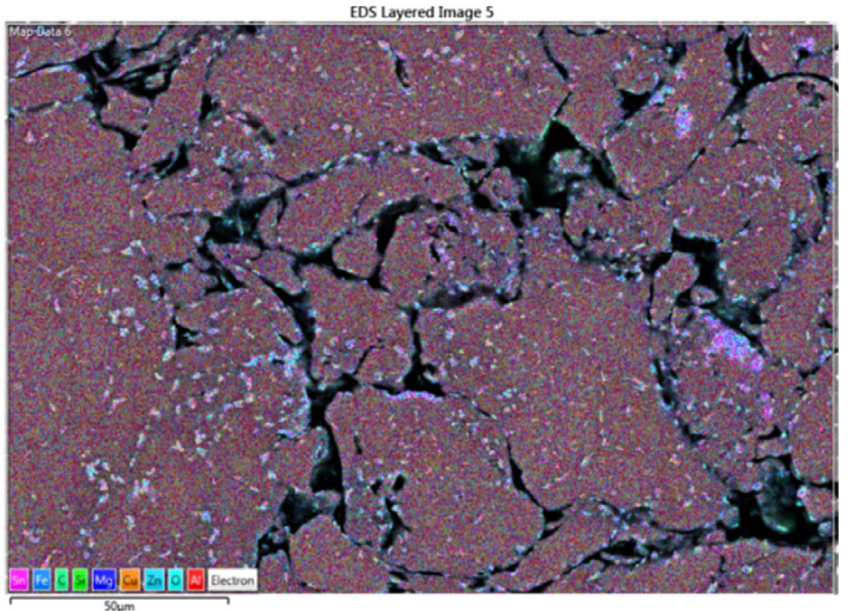

Zn K series

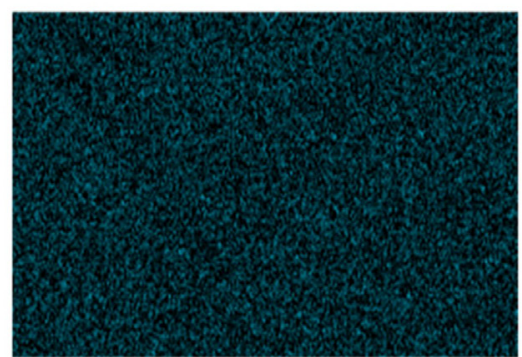

$50 \mu \mathrm{m}$

Fe K series

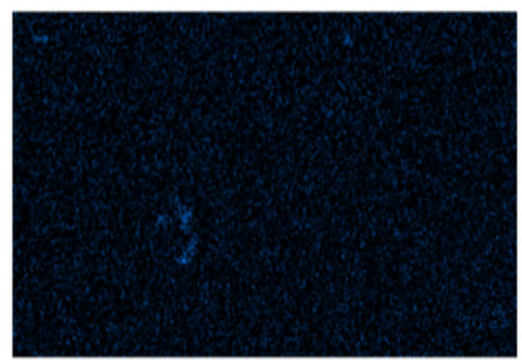

$50 \mu \mathrm{m}$

C K series

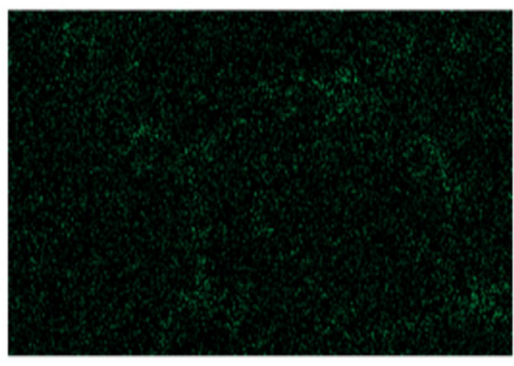

when content of MWCNT increased for more than $0.5 \mathrm{wt} . \% .49$ $\mathrm{HV}$ was obtained as highest hardness for this composite powder with $0.5 \mathrm{wt} . \%$ MWCNT and reduce with increasing amount of 

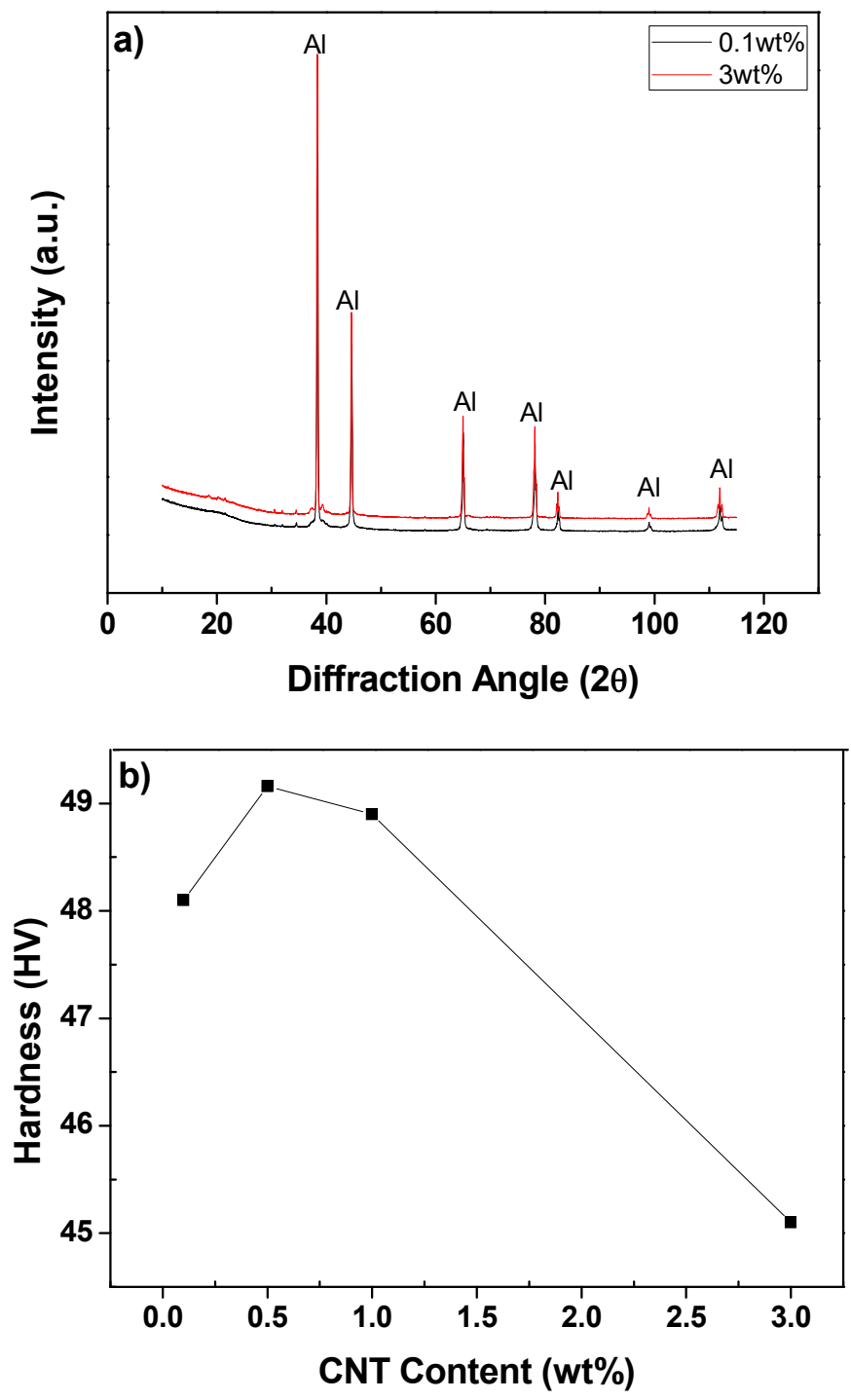

Fig. 5. a) X-Ray Diffraction (XRD) and b) Vickers Hardness of sintered Alumix 431D with MWCNT

\section{Conclusions}

Ultrasonication technique successfully dispersed MWCNT on Alumix 431D. Ultrasonication and low energy ball milling powders have similar raman characteristics, this indicates that the dispersion process did not affect on carbon structure of MWCNT. According to microstructures after sintering of these nanocomposites, it seems that there is agglomeration especially for material with MWCNT content for more than $0.5 \mathrm{wt} \%$. This agglomeration leads to lower sintering density and mechanical properties.

\section{Acknowledgements}

Support of the project NETME Centre PLUS (LO1202) funded by Ministry of Education, Youth and Sport and Czech Science Foundation

\section{REFERENCES}

[1] H. Kwon, M. Takamichi, A. Kawasaki, M. Leparoux, Mater. Chem. Phys. 138, 787 ( 2013).

[2] A.M.K. Esawi, K. Morsi, A. Sayed, M. Taher, S. Lanka, Compos. Sci. and Technol. 70, 2237 (2010).

[3] S. Simoes, F. Viana, M.A.L. Reis, M.F. Vieira, Compos. Struct. 108, 992 (2016).

[4] V. Giridhar, R.S. Arunraj, R. Dhisondhar, Inter. J. of Eng. Technol. Research. 1, 54 (2013).

[5] Tao Peng, Isaac Chang, Powder Metallurgy 284, 32 (2015).

[6] A.D.P. LaDelpha, H. Neubing, D.P. Bishop, Mater. Sci. and Eng. A 520, 105 (2009).

[7] H. Rudianto, G.J. Jang, S.S. Yang, Y.J. Kim, I. Dlouhy, Adv. Mater. Sci. Eng., 2015. 